\section{Narrative diagnosis}

\author{
John Launer
}

Since 2008, coroners' courts in the UK have allowed 'narrative verdicts'. They now accept that it is sometimes impossible to assign any single cause to a death, such as natural or accidental death. Instead of forcing juries to strive for the illusion of certainty, or to try and squeeze all the evidence into pre-ordained categories, the law now allows them to describe what has happened, to set out what is known and unknown, and to express their views in narrative form. This is such a sensible option, and so clearly fits with all the complexities and ambiguities of real life that it seems surprising that it took so long for anyone to come up with the idea.

It also makes one wonder why a parallel concept of 'narrative diagnosis' hasn't become established in medicine. Complexity and uncertainty are surely as common in medical practice as in the law, if not more so. As doctors, we often find ourselves having to try to name things for which there are no easy names, or struggling to pretend that something can be described by a single label when in reality it cannot. We are all probably guilty of offering a firmer diagnosis than the circumstances sometimes warrant, simply because we believe that is what we are required to do. As a profession we commonly invent labels for dubious 'grey area' conditions that we cannot fully understand or that refuse to fit into existing boxes. A narrative diagnosis would fit these circumstances very well.

Narrative concepts are of course already familiar in medicine. The whole field of 'narrative medicine' has expanded greatly in recent years, with a number of different schools of thought and practice flying under that banner. ${ }^{1}$ All of them share the same fundamental belief, namely that telling stories lies at the heart of human endeavour, and that patients and doctorslike everyone else-engage in continuous story-telling to make sense of their own experiences. Although no-one seems to have named the concept of narrative diagnosis before, many authors in the field of narrative medicine have addressed related topics, including the benefits and disad-

Correspondence to Dr John Launer, London Deanery, Stewart House, London WC1B 5DN, UK;

jlauner@londondeanery.ac.uk vantages of giving a medical name to someone's condition, and why we sometimes give names to problems that might be better off without any. ${ }^{2}$

\section{NARRATIVE THREADS}

In practice, we probably do use narrative diagnosis quite a lot, without necessarily being aware of it. For example, some of the most common statements used by general practitioners include 'there's a lot of it around', 'it's probably a virus', and 'it's likely to go away of its own accord'. These descriptions-one might call them narrative threads - all carry an important message: a formal, medical diagnosis may do harm, and keeping the conversation within the realm of everyday, colloquial story-telling may serve the patient better.

From observation, I suspect that doctors offer narrative diagnoses more often, and with more skill, as they become more experienced. Over time, they become better at tolerating uncertainty, and more confident in sharing this with their patients. A beginner might say 'you definitely have irritable bowel syndrome', while an experienced general practitioner or gastroenterologist might feel comfortable with a more elaborate but less certain narrative: 'I can't find anything physically wrong with you and the tests haven't shown anything. Your symptoms are pretty common and certainly don't seem to point to anything major. Some doctors like to call this kind of thing 'irritable bowel syndrome', and some patients find that kind of label helpful. It's fine for you to choose whether you like the term or not. Either way, there are several different kinds of medication that might help, and there are dietary changes that may make a difference too'

Although there are some patients who find this kind of professional transparency annoying, my experience is that the majority of patients prefer it to the alternative of deceit, sometimes accompanied by self-deceit, on the part of their doctors. I imagine that systematic research among patients would bear this out.

\section{POSITIVE OUTCOME}

One of the advantages of naming the concept of narrative diagnosis is that we may start to regard it as a positive outcome from a consultation, and possibly even a preferable one in many cases to the fetish of 'the firm diagnosis'. As well as making the relationship with patients more honest, it could also move the doctor's stance from a spurious search for certainty towards one of curiosity in the uniqueness of the patient's own story. If we accept that our expertise is often best applied in normalising people's difficulties rather than pathologising them, it might assist in passing power back from the physician (as a person who always has to understand what is 'really' going on) to the patient (who in many instances knows far more about what is going on than anyone else).

If we adopted the concept, we could also teach and learn the art of narrative diagnosis: when it is safe and when it isn't, how to deliver it in a way that is tactful and not dismissive, and how to be as authoritative about one's uncertainties as one's certainties. There is also an obvious overlap between using narrative diagnosis and actually providing narrative treatment. Offering a story that is not aggrandised by a medical term can itself be a form of therapy, especially in a patient who is anxious about having a serious underlying condition. A good narrative diagnosis could also open the door to discussing all the aspects of the patient's experience that might be closed down prematurely by medical labelling. To give an obvious example, calling someone's transient low mood 'depression' may be less helpful than saying: 'I can see and hear that your mood is low, but I'm really not sure why that is. Can you shed any light on it yourself?'

\section{RADICAL THINKING}

Beyond that, we enter into an even more radical area of thinking. In our best and more philosophical moments, most of us probably realise that even the most apparently solid of physical diagnoses ('asthma', 'hypertension') are often themselves only abbreviated narratives. They each refer to highly complex sets of ideas-scientific stories in their own right. ${ }^{3}$ Their meanings shift from one historical era to the next, from one country or culture to another, and sometimes even between different groups of practitioners or individual doctors. ${ }^{4}$ With exceptions such as peritonitis or cerebral haemorrhage, many formal diagnoses might be regarded more as vague but pragmatic signposts rather than absolute certainties. They indicate the general area or cluster in which someone's difficulties belong. However, these often have fuzzy boundaries. In some cases they may not 
even provide much helpful guidance about what to do next. Even a statement such as 'you've got asthma' is in some instances better replaced by questions such as 'have you ever thought of this as asthma?' and "what would be the advantages and disadvantages for you of doing so?'. 5

If you habitually say that sort of thing, there is of course a risk that some of your less philosophically minded patients might want to slap you. Some of your colleagues might be tempted to do so as well. Even so, it is worth reminding them that the exchange of narratives, or at least of narrative threads, is the activity that occupies most of the time that doctors ever spend with patients. Outside the technical specialties such as anaesthetics or radiology, it may fill the vast majority of our working lives. Among all the medical competences we need, none lies at the core of what we do more than 'narrative competence'. 6 One essential aspect of this must surely be the ability to deliver a good narrative diagnosis.

Competing interests None.

Provenance and peer review Commissioned; internally peer reviewed

Postgrad Med J 2012;88:115-116

doi:10.1136/postgradmedj-2011-130685

\section{REFERENCES}

1. Kalitzkus V, Matthiessen P. Narrative-based medicine: potential, practice and pitfalls. The Permanente Journal 2009;13:80-6. http://xnet.kp.org/ permanentejournal/winter09/narrativemedicine.html (accessed 11 Dec 2011).

2. Mayou R, Kirmayer L, Simon G, et al. Somatoform disorders: time for a new approach in DSM-V. Am J Psychiatr 2005;162:847-55. http://ajp. psychiatryonline.org/article.aspx?articlelD $=177513$ (accessed 11 Dec 2011).

3. Montgomery Hunter K. Doctors' Stories: The Narrative Structure of Medical Knowledge. Princeton: Princeton University Press, 1991.

4. Gabbay K. Asthma attacked? Tactics for the reconstruction of a disease concept. In: Wright $T$, Treacher A, eds. The Problem of Medical Knowledge: Examining the Social Construction of Medicine. Edinburgh: Edinburgh University Press, 1982.

5. Von Schlippe A. Talking about asthma: the semantic environments of physical disease. Fam Sys Health 2001;19:251-62

6. Charon R. Narrative medicine: attention, representation, affiliation. Narrative 2005;13 $261-70$.

\section{Warwick University short courses}

2-5 July 2012

Techniques and applications of molecular biology: a course for medical practitioners A 4-day course for those in the medical profession wishing to improve their understanding of the principles and applications of genetic engineering techniques. Optional accreditation leads to a masters level Postgraduate Award.

Details: Dr Charlotte Moonan, School of Life Sciences, University of Warwick, Coventry, CV4 7AL; tel: +44 (0) 247652 3540; email: charlotte.moonan@warwick.ac.uk; website: www.warwick.ac.uk/go/lifescienceshortcourses

\section{3-14 September 2012}

Laboratory skills

A course for those wishing to gain hands-on practical experience of vital and fundamental laboratory techniques.

Details: Dr Charlotte Moonan, School of Life Sciences, University of Warwick, Coventry, CV4 7AL; tel: +44 (0) 247652 3540; email: charlotte.moonan@warwick.ac.uk; website: http://www.warwick.ac.uk/go/labskills 